\title{
Organizational Management through Effective Leadership in Diverse Environment
}

\author{
Angela Samundengo* \\ Zambia \\ *Corresponding Author: Angela Samundengo, Zambia
}

\begin{abstract}
Effective leadership plays a critical role in organization management setup. The concept of effective leader in practice, is at the center of organizational success that capitalizes on effective human resource. Organizations need effective leaders to manage its strategies and implement its objectives effectively and efficiently to achieve its intended goal and great performance. Literature on effective leadership and management practices in organizations, indicate that many scholars have taken keen interest to research on organization's management, leading to great performance and implementation success, while considering challenges that impact on organizational leadership, management and its applications.

Critical review of previous studies such as, Weinberg (2014), Dowsett (2006), Yukl and Lepsinger (2004), (Walden, 2014), reveal that many organizations need knowledge in order to be successful and manage competitiveness in diverse environment of doing good business for their survival, (Kumar et al, 2013). Such knowledge can be turned in action by effectiveness of the leader to guide employees as they execute their tasks on a day to day basis.

This research study focused on effective leadership, narrowed down to the education sector in Zambia's primary education, focusing on effective school leadership and management for improved performance. This research study was inclusive as it considered various players such as private and public organizations, including non-governmental organizations (NGOs) with operations in Zambia and outside.
\end{abstract}

\section{Issues About Effective Leader And Management Impacting Organizational Performamnce}

Research shows that there have been many studies on leadership and management in order to assess its impact on organizational performance. Despite past and ongoing studies on the topic of leadership and management, it is still not very clear whether there has been direct and positive impact on organizations performance, as a result of effective leader and management practices in organizations and its project and program implementations.

In this research study, a focus on leadership and management best practices, provides solutions upon which businesses can reflect upon and learn. This process is in an effort to improve their organizational leadership and management for success and greater performance for organizations. Discussions and results of this study have some answers to questions which are often asked such as:

$>$ Why some organizations still thrive even in harsh and diverse environment while others fail? Is it because of its management style, leadership or both?

$>$ Why do organizations cultivate innovation, strategies and risk management in its overall management, leadership and implementation?

$>$ How do organizations evolve around current issues that would have a direct and or indirect impact on its overall performance?

In responses to such questions, this research study has revealed that, Organizations need effective leaders and managers. This group of employees who can manage and guide followers effectively and efficiently. They are needed in order to drive and implement organization strategies and deliver on objectives effectively and efficiently. Leaders are expected to have certain traits that an organization needs for its high performance, leading to success. While there has been interest to research on organization's performance and project implementation success, they have done so while considering challenges in organizational leadership, management and its applications and have contributed greatly in finding solutions to these problems being discussed. 
It is noted that other scholars have taken a step further to research on differentiated leadership in organizations with the aim to understand the diversity of leadership and their impact on organizational performance. Such examples of research on the topic refer to "responsible leadership", (Walden, 2014), this has taken the questions on leadership in organizations yet to another level.

Similarly, a review into leadership activities and their impact on creating knowledge in organizations, reveals that many organizations need knowledge on what is leadership. Knowing how it can be applied in the implementation of its strategies in order to be successful and manage competitiveness in the diverse environment of doing good business for their survival, success and continuity (Kumar et al, 2013).

\subsection{Effectiveness of Leadership in Public Organizations}

Leadership and its effectiveness or its impact on organization performance can be measured easily if there are deliberate tools put in place strategically by management.

However, when it comes to public sector, such measurement has many challenges and its intended purpose tend to be frustrated by many external factors to the organization such as politics which may affect performance and effectiveness of leaders.

According to a study on public organization and leadership, measurement of effectiveness on leadership, seems not to be common practice among public organizations. Therefore, its value and the long term impact on the organization seem not to be appreciated by many people in those settings.

This finding can also be associated and is assumed to affirm the struggles that many public institutions are faced with today with regard to leadership issues. Today, specifically, many Government departments encounter challenges that are centered on issues of management and effectiveness of leadership, (Fairholm, 2004).

Similarly, if you take a closer look into details of many public organizations which have failed to thrive in harsh economic environment, they all have similar threats and pressure, for example from politicians who have taken advantage of the organizations leadership. Such external forces onto the public organizations can only be proven to be overcome by effective leadership and strong management who can defend and protect its policies and strategies established for the organization's long term growth and survival.

Therefore, there is need for public organizations to take leadership engagement activities that aim at training its leaders and management to become effective in their positions as they execute their duties and deliver on the organization objectives and strategic goals. Such activities need to engage leaders in their roles as they exercise their leadership skills in the implementation of their duties and with support from internal and external experts. It also means that such leadership strategies and activities need to be cultivated throughout the implementation at all levels of the organization in order to be appreciated in its implementation by all employees.

\subsection{Effective Leader in Practice}

In order to be an effective leader, a lot need to be put in place at an individual level as well as the psychological aspect of the leader. An effective leader requires self-consciousness and discipline in all areas of action, interaction and step up for decision making.

An effective leader is to be proactive in taking decisions as opposed to being reactive to issues as and when they arise. It is about being creative in order to find solutions to the most challenging issues of the organization.

An effective leader is perceived to have a bird's eye. One who sees above other people's eyes. A leader is able to see all issues critically and beyond what others can perceive and critic, reflect and take positive action in order to arrest an upcoming situation and point it into the right direction. A visionary leader who analyses situations and suggests and implements great ideas which result in solutions that cater for both long and short term interests of the organization and all its stakeholders.

Effectiveness of a leader requires learning and practice, (Anderson \& Adams, 2016), and is considered in leadership development as a life learning skill, (Castellano, 2014). It is a continuous process of leaning and how to pass the knowledge to those around you in order to foster and instill knowledge practically for the purpose of growth of the Organization and its good performance. 
Effective leader is about "discerning purpose of the organization, instilling vision of the organization in others, it's about knowing your doubts and fears and be able to guide others, to engage in authentic and courageous dialogue on behalf of the organization and its followers or employees and all stakeholders, it is about developing intuition, opening inspiration and thinking systematically". An effective leader needs to be courageous and be able to speak about the interests of the organization that would lead to its success and exceptional performance overall.

In fact, many scholars that have focused their effort to study on organization leader performance by analyzing the qualities and skills of those in the driving seat, have realistically assed and concluded that, an effective leader attracts many followers and finds his/her fit within the followers environment, thereby encouraging others to contribute their best effort to improve organization performance that leads to greater success.

Such leaders are trusted and perceived to be truthful in all their dealings by their followers and all stakeholders that entrust them with responsibility. They are role models in truth, integrity, honesty and trustworthy and they represent and speak a true reflection of their organization and those varied stakeholders to the organization.

Leaders in general, manage an organization and ensure its success in all areas of operations. This means that an effective leader must also be an effective manager as the two roles work hand in hand. Leadership in itself has ups and downs, as no leader is perfect. However, once a positive mind is applied while leading an organization and a team of employees, it is believed that leadership is learnt through experience and over time.

Mistakes made in the process are the building blocks that lead to the next step on the ladder to effectiveness of leadership. The pieces of mistakes when picked up and, put together, they are the ones that teach us how to re-pack the pieces correctly and help us to become creative in order to find solutions to stumbling blocks in the path of success for leaders.

An effective leader is believed to be a visionary leader. This is because they focus on achieving organizational goals through effective operationalization of the overall organization strategy and objective which is aimed at a long term growth. This means that the leader is at the center of ensuring that implementation takes place and organizes and motivates the team to be at the top of their roles and responsibilities.

The leader ensures that resources are available at all time and at every stage of implementation to enable smooth support and technical operations. The leader ensures that the right personnel is in place and are technically skilled and motivated to deliver effectively. The effective leader knows that he or she is responsible to all stakeholders including employees, sponsors and the direct beneficiaries of the Organization. Therefore, he or she is fully aware of the environment and has a responsibility for the down falls or success of the Organization as a whole.

According to, (Kridler, 2016), "great managers always create and guide employees who are believed to energize the organization". The scholar further alluded to the importance of giving employees an operational space where they could use their skills to effectively deliver as opposed to being monitored and influence on how they technically operate to deliver on their expectations. This is indeed true when one considers how todays skilled employees apply their knowledge in their day to day in applying the most improved technology available.

Actually, an effective leader who has the best interest of the organization at heart, needs to know and understand every corner of the organization's implementation requirements in order to appreciate the existence and meaning of every employee's role. The leader may not be able to technically know, for example how to fix a machine, but their knowledge of what is required to operate the machine will help to provide the much needed management support at each level of operation. It is the passion that the leader has for the organization that matters most, as this brings about high achieving targets naturally, (Fox, 2017).

A visionary leader pays attention and ensure that all organizations operational goals are at all times of implementation aligned to the Organizations' long term strategic goals and objectives. It is such foresight that earns an effective leader respect from his or her followers. This is because, subordinates or followers can trust that they are able to implement their activities within the organization and that 
they have someone who is able to understand and support their contribution to the organization through their varying roles positively.

Businesses are operating in a very dynamic environment with many ups and downs. If an Organization is to succeed in such harsh environment, there needs to be set objectives and an operational strategy, which would guide employees and its leaders. However, according to (Dowsett, 2006), having a strategy and objectives in place is not enough, because an organization can still succeed or fail depending on who is in the driving seat.

An organization needs to have a "quality and an effective" leader in order to be successful. It's about finding a right and a working model for the organization which needs to be learned and applied throughout the execution of the organization strategy and objectives in order to reach its intended goal, (Yukl \& Lepsinger, 2004).

An effective leader ensures that he or she has a team that is skilled technically in their role and that there is continuous learning for the team in order to deliver the best of their expectation. This means that the effective leader continuously engages and brings everyone on board to ensure every employee understands the organization's vision and appreciates it in order to ensure that every effort contributes to the organization overall goal and its strategic objectives.

\section{Rationale: Effective Leader in Zambia Public Primary Education and Selected Public ORganizations AND NON-GOVERnMENTAl ORganizations (NGOS)}

This research study was targeted at effectiveness of leaders in selected private and public organizations which include public primary education in some of the provinces of Zambia. In public primary education schools, this research survey targeted school leaders who are the school administrators and are entrusted with responsibility of ensuring that the school is managed in the most effective and efficient way. Ensuring availability of resources in both staffing of teachers and financial resources for smooth running of the school and implementation of school curriculum.

In other organizations other than schools, such as NGOs (local and international), who participated in the this research study, targeted at staff in leadership roles, human resource and those that are familiar with leadership strategies and its implementation in their respective organizations.

This research study has been a buildup on to many research studies undertaken in the past by different scholars in an effort to find solutions to bottlenecks in the implementation of many performance activities. In most organizations and in public primary schools, these performance activities are under the directive of school administrators and managers.

Realistically, and evidently, in the past, it has been researched and documented fact that there has been significant trends in failures and little success in many organizations and their performance which has raised questions about inconsistences for players within the same environment. Some of these questions relate to why some organizations and schools, despite having leadership and similar composition of employees, teachers and number of students still fail to deliver on their mandate, while others succeed in similar environment.

This research study provides some of the solutions needed for improvement in leadership and effectiveness in order to improve overall organization performance. However, not to say that such studies may provide full solutions to the success and failure experienced by many organizations and schools, it is expected that the results may suggest solutions that reduce the existing effective leadership gap.

While the study seemed straight forward, the process came with many challenges as access to some organizations and some schools to administer the questionnaire was limited. Major challenges were about participants not being open to fully complete the questionnaire despite assurance that their details will not be disclosed without their consent. Other challenges included distances between schools where data was collected with poor infrastructure in rural Zambia.

\section{Methodology}

\subsection{Research Materials}

A pre-designed and tailored questionnaire to specifically meet the needs of this research study was used in the collection of data. In order to collect data that is representative of the country, organizations and schools were sampled from 5 provinces out of the total 10 provinces in Zambia. This questionnaire was sent to participants through a combination of email and hand delivery. 
Participants were given a maximum of 30 days to complete these questionnaires and were asked to return them via different and the most efficient and less cost effective means which ranged from scanned and email documents to hand delivery depending on the rural location of the school.

However, due to challenges of transportation and communication, feedback on questionnaires took much longer than anticipated. This delayed the analysis of the findings within the anticipated 90 days.

Participants had an option to either disclose their identity or not as disclosure of identity of the participants to the research study was not mandatory and this fact was clearly stated in the questionnaire.

\subsection{Strategy and Techniques}

This research study focused on the theme "Effective leader" for improved organizational performance in the modern environment where there are so many challenges encountered by organizations in doing good business. Particularly, many organizations encounter diverse challenges in general that are either as a result of internal engagement within the organization and in some cases external to the organizations.

Usually, challenges from internal engagement can easily be dealt with and eventually, in many cases solutions are easily found.The study brings out the real experience of leaders when managing public institutions and their lessons learnt that can be shared widely in diverse environments.

Challenges from external factors are usually very difficult to deal with as there is less or no control, mainly from internal organization management over influence against strategies set for short and long term basis. Some are imposed upon by financiers to the organization and therefore increasing their vulnerability in the way they respond to external forces. In many cases, political influence on an organization is an external force that potentially affect how an organization responds to some forces external to the way they are used to in dealing with their clients.

In order to make sure that data collected is comparable across sectors within Zambia, this research and data collection was extended to other organizations other than public primary schools. These additional organizations are mainly NGOs operating in Zambia of which some have operations in other countries. A few other public organizations with operations in Zambia were also targeted in this research study. Some of these public organizations were included in this research because they are perceived to be going through a lot of operational challenges as perceived by the public. Therefore, their inclusion in the study brings a lot of diversity in dealing with leadership and its effectiveness in large public institutions.

\section{Data Analysis AND Results}

The analysis and results of the research data has been based on two main categories. These categories include the nature of institutions that had participated in the data collection and the geographical location where data was collected. These two categories provide a lot of diversity in the way institutions encounter varying challenges in an effort to efficiently and effectively manage their operations for improved overall performance and long term growth in a very diverse environment.

An effective leader will either succeed or fail by considering the environment in which they are operating and those around them to support their effort.

Data has further been analyzed in an effort to give the reader a greater sense of comparison by looking at the categories that bring together a holistic picture that affect the organization's overall performance and character.

The research looked into an organization critically by considering all aspects that influence the playing ground for leaders that supports their effort as leaders to effectively execute their duties. These aspects consider both the internal and external environments to the organization.

\subsection{Research Data Collection and Participation}

The research study pinned down on issues that institutions practice which center around developing an effective leader within an existing team. It considered whether an institution had a strategy in place as a pathway to effective leader development that cuts across the organization and provide equal 
opportunities to deserving employees to develop and exercise their leadership skills effectively for the benefit of the organization.

The research study delved into a more detail of categories that brought the results of the study to a more meaningful analysis and ensure that data made sense. The research questions further looked into issues of whether the organization or institution had taken its leadership strategy further by engaging in organizational wide activities that promote employees ability to become effective leaders in all their areas of engagement. Those activities are the ones that contribute to the organizational goal of high performance.

The study further touched on questions that relate to the effective leader activities that lead to success and failures in the execution of the organization strategy on effective leader. This aspect brought about lessons learnt and gave insights on how such strategies could be executed in a leaner and efficient manner which aims at benefiting all participants in the implementation of the strategy and indeed those who did not or may not have had the opportunity to benefit directly from the organizational strategy implementation.

Although there was and seemed that the research data had many differences from the different organizations which participated in the study, there was one common goal in the organizations. This goal was to ensure that there was an effective leader whose aim was to ensure that the organization's performance overall was exceptional and comparable.

The overall research data collection indicated that nearly all organizations and institutions that participated in the research study, clearly indicated that such organizations had an existing leadership strategy in place that was aimed at ensuring that employees exercised their leadership skills effectively and efficiently for overall organization improved performance. However, what was not clear to many participants was the operationalization of the strategy and how it impacted those who benefited from its execution and the overall impact on the organization performance.

\subsection{Geographical Location of Data Collection}

Data was collected mainly from 5 provinces of Zambia out of 10 provinces which represents about $50 \%$ of the total provinces and the presence of the participating organizations location country wide. A few other organizations which participated in the survey already had representation in all provinces in the information provided for this analysis.

Such provinces from which data was collected are Central Province, Eastern Province, North Western Province, Southern Province and Western Province. Other data representation was collected from Lusaka Province for some of the organizations which participated in this research survey.

There were a total of 50 questionnaires which were administered in all the provinces mentioned above. Out of the total questionnaires administered, only 35 questionnaires were fully completed by the participants. This total of completed questionnaires represents $70 \%$. The remaining 15 questionnaires which were either partially completed or not filled at all represent $30 \%$ of the total administered questionnaires. These 15 uncompleted questionnaires were from all participating provinces.

Despite having all administered questionnaires not completed, those $70 \%$ completed brought out the much desired data that has enabled a meaningful analysis of the issues around effective leader in many organizations.

\section{RESEARCH RESULTS}

\subsection{Interpretation of Results}

The research questions were centered on 4 main categories as follows:

a) Existence of leadership strategy in the Organization;

b) Activities which were aimed at enhancing an effective leader in the implementation of the leadership strategy in the Organization;

c) Evidence that success factors from the implementation of the strategy that existed;

d) Lessons learnt which can be shared and discussed for the benefit of other organizations or other players in the environment; 


\subsection{Existence of Leadership Strategy in the Organization}

This question was probed in order to understand the situation of the organization with regards to whether there was an existing strategy which all of its employees were aware of. Knowing the situation of the Organization enabled the follow up questions in the questionnaire much easier and straight for the respondents.

There were a total of 35 fully completed questionnaires and respondents did very well in providing answers to the question on existence of the strategy on effective leader in their organizations.

Out of all responses to this question, 32 respondents were very much aware and agreed that leadership strategy on effective leader indeed existed in their organizations. However, there were many differences on how each and every organization managed the implementation or operationalization of the effective leader strategy. All 32 respondents were from either public primary education, NGO or public organizations.

On the other hand, generally, employees who were very much aware about the existence of the effective leader strategy in their organization seemed very enthusiastic as they were able to foresee the bigger benefits that could benefit the future of the organization overall and indeed their own benefit in the long run.

2 of the respondents indicated that their organization did not have a leadership strategy in place, while one respondent did not know or were not sure whether their organization had a leadership strategy in place. Refer to Graph1 below.

Just as much as each of the organizations had the leadership strategy which is meant to benefit employees on merit, most of the respondents expressed concerns on how their leadership appointed who would benefit from the operationalization of the strategy.

However, there was also a general expression that the idea of maintaining such a strategy is very good as its aim is to positively benefits employees and the organizational overall performance in the diverse environment of doing business and its long term existence.

The category of public organization other than the public primary education, 1 participant indicated that they were not sure whether a strategy on effective leader was in existence in their organization. However, they were able to observe that some activities that the organization was implementing could be linked to leadership as outlined in the questionnaire.

It seems that some organizations have not explicitly put their leadership strategy to its workforce and engage them in its implementation. Hence I see that some employees see this at glance and don't get closer to understand its benefit to them as employees and indeed the organization overall.

I see in this research study that most organizations fail to bring all pieces of their strategies meant to be implemented by all employees. This leaves employees to distance themselves and perceive that such is only meant for those employees who are already in senior management and it does not concern them in any way. Therefore, they go about their normal business each day without being part and parcel of developing the organization future and its wellbeing.

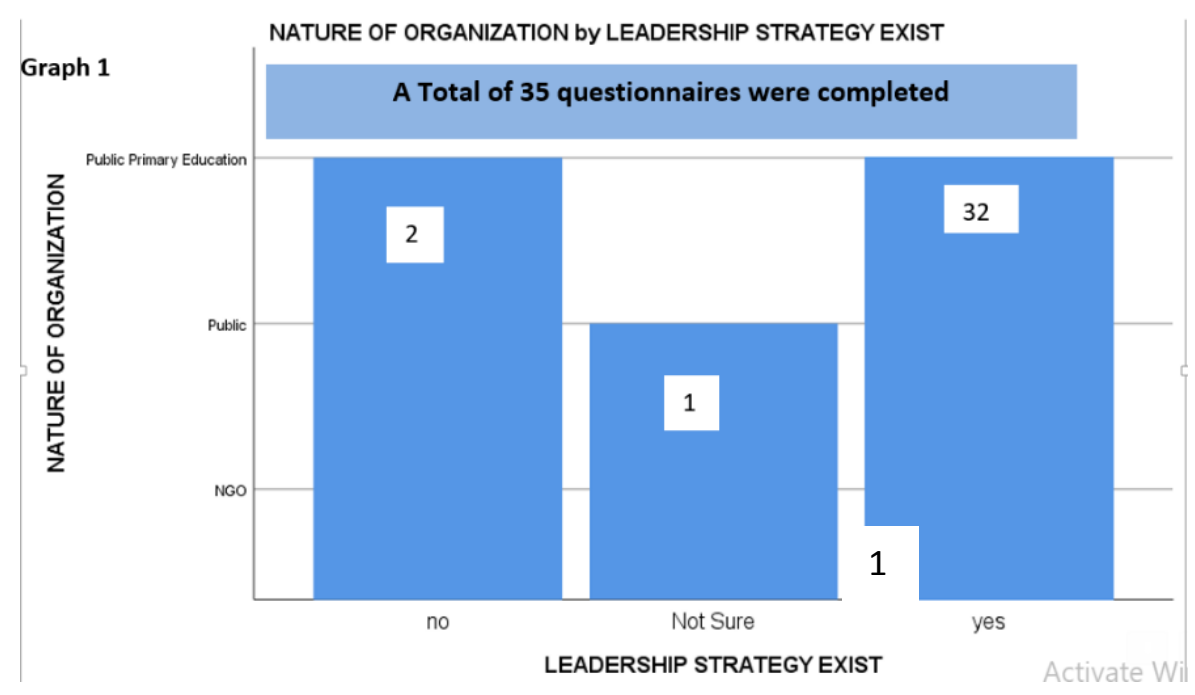




\subsection{Activities Which were Aimed at Enhancing an Effective Leader in the Implementation of the Leadership Strategy in the Organization}

The second set of questions were about whether each of the organization that had confirmed as having a strategy on effective leader in place. The objective was to understand how the strategy was implemented and how it benefited its staff in ensuring that its leadership was effective towards overall organization performance.

This question brought about very interesting responses as the experiences differed greatly from organization to organization. Although many of the organizations differed mainly in their location and management, more for public primary education, ultimately, it was very clear that the implementation of the strategy was influenced by its internal leadership and management approach depending on their unique internal situation.

The study result clearly indicates that the approach to take on deserving employees to participating in organized activities that aimed at building capacity of effective leaders within an organization was not in many cases based on merit.

Due to lack of clarity on how employees are engaged on the capacity building program, resulted in some employees not appreciating the benefits of such a strategy and implementation of activities aimed at effective leader to them as individuals and an organization as a whole in the long and short term.

Reasons for lack of clarity on the part of employees was mainly attributed to lack of communication to all staff about the effective leader strategy and how it would be implemented. There was a missing effective communication from the institutional leadership to all staff within their institutions.

Organizations such as the public, other than public primary education and the NGOs had in most cases a clear implementation approach to the capacity building program for all staff. However, there was still a concern that was common among this category of organizations. This concern was about who of the staff would qualify to be on the effective leader program.

It was perceived that only employees who were already in senior leadership positions benefited for every capacity development activities. Those employees below the senior leadership category or level did not have an opportunity to be involved in the activities.

Although it was well known by management that these employees in most cases had a very huge potential to build their leadership skills for the benefit of the organization overall. This approach created a lot of negativity by employees towards the leadership program and raised questions on its real objective.

Due to unclear approach of strategy implementation in most organizations, some participants expressed concerns that they did not see real benefit for the strategy. It was seen and perceived by many as a waste of resources and time that could be put to better use.

Other issues that were cited was that, some individuals did not transfer their learnt skill for the benefit of others and the organizations as a whole. They could not see any improvements in their approach to issues which centered on leadership within their capacity to lead a team and the organization in a very competing environment.

However, on the other hand, organizations which had a clear approach which considered staff at all levels noticed great improvements in its leadership and approach towards organizational performance. Staff felt that they were part of the winning goal and therefore, their contribution had a purpose which was very clear to them from the inception of the strategy implementation.

Graph 2 below clearly shows that out of the 35 respondents, only 1 respondent from one of the participating organizations from the public, other than public primary education did not have any activities organized or arranged towards implementation of the strategy. However, the respondent clearly confirmed that indeed, there was a strategy on effective leader that existed in this organization.

What was most interesting about this organization is that there was no plan as to how that strategy could be implemented. This brings us back to why organizations need to have effective leaders and it would be most beneficial if the effectiveness of each leadership can be measured. 
Similarly, out of all public primary education institutions that participated in the research study, only 1 did not implement the strategy. Employees are very much aware that its leadership needs to help implement the strategy, but wondered why that could not be done.

Public primary education institutions only had 1 institution or participant that did not know whether there were any activities aimed at implementing the effective leader strategy. In other words, the participant did not know whether the strategy had an implementation plan or approach. However, the participants highlighted that there were some selected individuals that had been given the opportunity to improve their leadership skills at a very small scale.

It was interesting to note that out of the total 35 participants, 33 participants from public primary education were very sure and confirmed that there were activities lined up each year which are aimed at implementing the effective leader strategy.

There was 1 participant who confirmed the existence of implementing activities from the NGO. There was also 1 participant from public organization other than the public primary education who confirmed that activities aimed at effective leader strategy implementation were in existence.

The majority of respondents that confirmed implementation of the effective leader strategy were from public primary education.

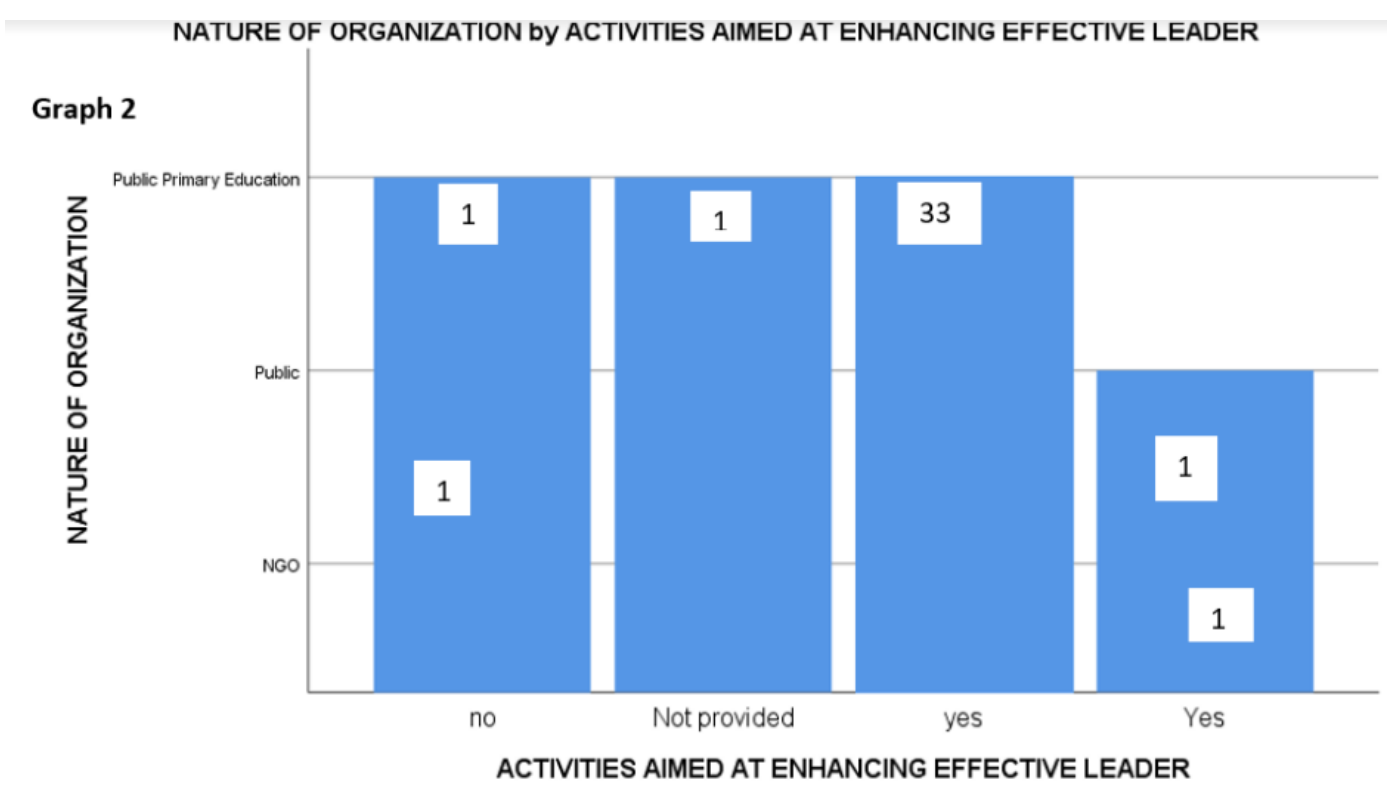

Evidence of Success Factors From Implementation of Effective Leader Strategy

A third aspect that was considered in this research study was to understand whether there were any success factors from Implementation of the effective leader strategy by all the participating organizations and institutions. Not only did the question bring about successes, but also considered whether there were any failures, understanding what were the main issues around failures in the implementation of effective leader strategy.

Generally, there was a notable response which indicated that there were successes in many areas which colleagues could make reference to. These successes were thought to have brought about positive changes in leadership style and decision making by those who were engaged on the capacity development program on effective leader. Respondents also indicated that even though there was notable good signs, a lot more still needs to be done in order to have a very good positive impact on all staff and the organizations overall performance.

Participants cited issues of commitment from both employees and management in order to make such a strategic program a success now and in the longer period. They had appreciated the fact that their organization had embraced effective leader strategy as one of their strategic goals for the better survival and overall performance of the organization. This is one of their wins to manage and work around many challenges that organizations encounter in the competitive environment.

Some of the success cited were that, there was notable positive change in the way staff who benefited from the program managed their decisions in their day to day tasks. There was improvement in the 
way they engaged with colleagues at different levels within the Organization. There was also notable improvement in the way they engaged with external clients to the organization. The participating organizations by their nature had engagement with partners or allies, such as the communities within where the public primary education sites were located. This means that there was need for school leadership to engage heavily with the communities.

Respondents to this research survey indicated that there was a notable and very good engagement between the school leadership and the community. They were able to engage positively and improved on issues which concern the welfare of both the school and the community at large.

The respondents wished that the effective leader capacity development program is extended to all staff at all levels in order to have an organizational wide performance improvement efficiently and effectively. They see that in their organizations, only those in senior positions benefit from such programs, thereby created a gap within the employee development structure of their organization.

Individuals improved their personal organization which colleagues were able to spot as a follow up on their engagement on the leadership program capacity development and during the process of the capacity development. Their interaction with different individuals greatly improved and this was notable by many colleagues.

On the down side, respondents generally expressed concerns which were notable as main cause of failure on the implementation of the strategy on effective leader. They mainly cited such issues as main causes that lead to organizations failure to effectively implement. Poor attitude towards commitment to the program by those engaged in the capacity development.

The fact that the appointment or selection of who should be taken on the program in many cases is not based on merit, but the position which individuals already hold, leaves much to be desired. Most employees engaged on the program don't appreciate and know the objective of the organization. They only see the appointment and engagement as a privilege.

Other challenges that were cited are that, most organizations lacked financial resources as most of the engagement for effective leader capacity development need external support that require financial resources. Considering that there could be minimal resources available, only a handful number of employees are engaged on such programs.

Other concerns were that, staff who were engaged already on the program had no skill or capacity to transfer knowledge to other staff within the Organization. Ideally, they would be expected to give others on the job training to benefit internally by other staff knowledge attained from the trainings or engagement.

It was also noted that the same staff are selected for any follow up capacity engagement without much added value to the organization as a whole. The lower level staff felt sidelined and not considered even when they felt they had the potential to contribute to the wellness of the organization and its growth in a positive manner.

In some cases, respondents highlighted failures being attributed by external factors that negatively impact effectiveness on leaders such as witchcraft practice by fellow colleagues and community, negative attitude by the community who do not support efforts of the organization within the community. Other factors mentioned are political interference in positive decisions taken by the organizations leadership.

Graph 3 provides an outline of successes by nature of the organization. A total number 35 of questionnaires were completed on the question of noted successes from the implementation of the strategy on effective leader.

There were a lot of learning points which came out to understand the successes and also failures or challenges encountered during implementation by the different organizations.

There were 32 respondents from the category of public primary education. Out of the 32 respondents, 3 indicated that they did not see or note any successes which follows implementation of the strategy.

A further analysis into these respondents indicate that these institutions that reported no success had earlier indicated that there were no activities undertaken to implement the strategy that they have in place. In other words, they do not have an implementation plan despite having a strategy on effective leader. 
Again, this brings us back to why it is important to have an effective leader in an institution. When institutions or organizations have effective leader, no strategy put in place remains unturned. An effective leader will always remain goal oriented and this is why it is important that organizations realize and appreciate such leadership capacity development programs.

In the same category of public primary education, 2 respondents indicated that they had no information on whether there were any successes or failures in the implementation of the strategy. They simply did not provide information on this part of the question. Similarly, they had no answers to questions on whether implementation existed in their institution.

A total of 27 respondents from the public primary education responded positively that there were successes and they provided a good number of examples and benefits to the individuals and organizations as a whole.

Another category of respondents 1 participant from the NGO responded having recorded successes following the implementation and wished that if the implementation of the strategy was replicated at all levels in the organization, the success would be exceptional for their organization.

Last but not least category of organization from public institution other than public primary education, reported very positive successes from implementation of the strategy. However, the respondent expressed concerns in that only a few selected people benefit from such opportunities and it's not clear how the selection of those to benefit is done.

Due to the nature and size of the organization, you cannot assess whether selection is done on merit and what criteria is used. All in all, the respondents appreciated the fact that the organization management is in support of the effective leader strategy.

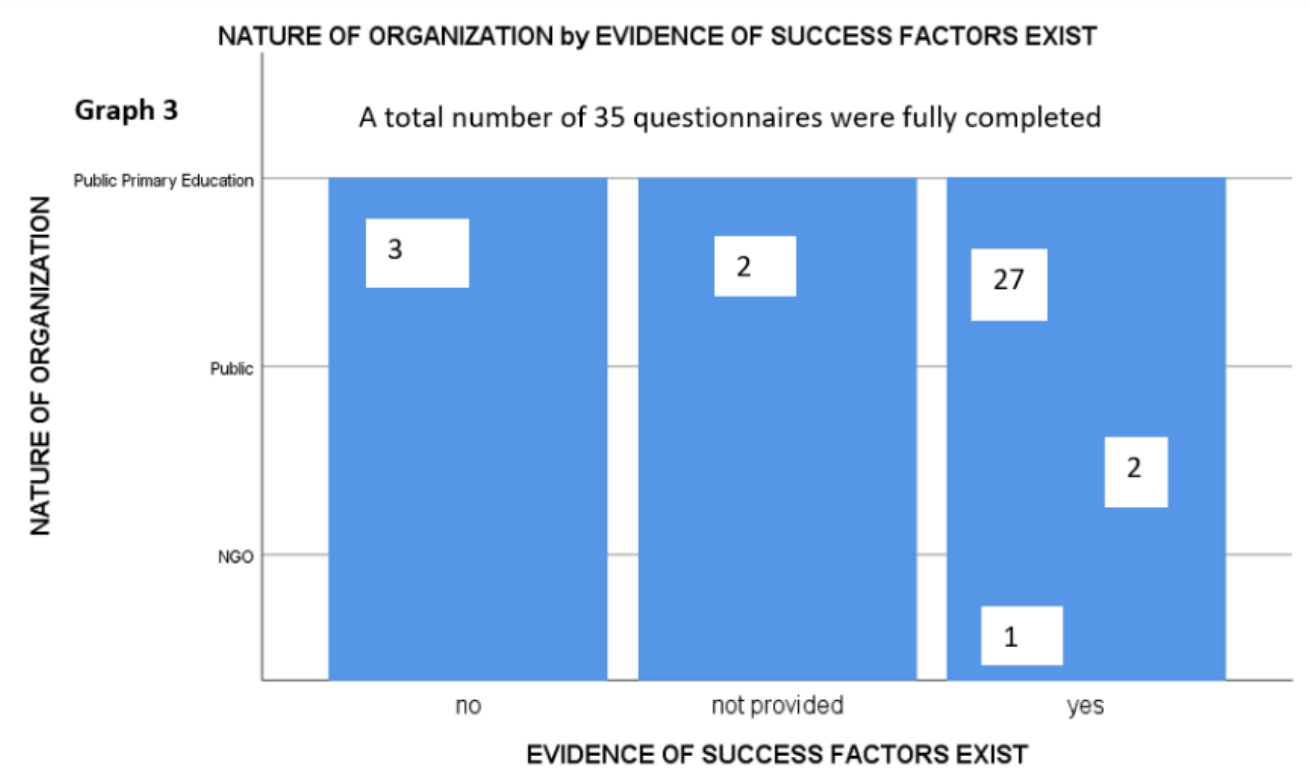

\subsection{Lessons Learnt From Implementating Effective Leader Strategy}

One of thekey research questions was for respondents to state whether there were any lessons learnt from the implementation of their organization effective leader strategy. This provided an opportunity to highlight those learning points and whether they were able or willing to share those learnings with other organizations who have embarked on similar mission.

Responses had many learning points. These responses highlighted the following as learnings that could be shared as benefits of implementing leader capacity at all levels of an organization. The lessons if well managed and implemented, could lead to high performing organizations which can be desired for one to be a part of.

a) It was notable that, generally there was improved work culture;

b) There was improved communication among staff;

c) There was noticeable improvement in commitment to duty by staff who initially were not committed before being engaged on the effective leader capacity program; 
d) They noticed that regular management meetings were held which actualized their organizations vision through those regular management meetings;

e) Team building among staff were enhanced, thereby creating trust among staff as they deliver on their mandate in the organization;

f) They noticed improved institutional performance;

g) Improved relationship among employees;

h) Improved pupil/student performance;

i) Enhanced participation of everybody at all levels in the affairs of the organization.

j) There was improved record keeping of organization valuable documentation;

k) Involvement in skills evaluation at all levels

1) Improved time management

m) Improved decision making skills

The above list is not exhaustive as respondents to the research questionnaire had many lessons which they wished they could share with those organizations who have embarked on the effective leader development for their staff.

\subsection{Research Summary}

This research study has answered the three research questions which were the main reasons why this study was undertaken. Reason being that, the results of the data analysis from the research survey questionnaire administration has provided details as to why some organizations exceptionally manage their performance regardless of high negative environmental conditions.

It is also notable that, having effective leaders in an organization provides a huge difference in the overall organization performance in the short and long term periods.

\section{CONCLUSION}

Research studies undertaken by many scholars has proved that effective leadership in any organization has a great impact on the success or organization's execution of its activities and lead to its long term sustainability, especially in diverse environment in which it functions.

Equally, the impact of effective leadership in an organization is also seen in individual personnel performance and their attitudes toward the positive success of businesses they are engaged in. As noted in the results above, there are accounts of lessons from the implementation of effective leader strategy by organizations which participated in the survey.

As a result, this research study result has provided more insights into new findings on leader development and effectiveness that would result in positive impact in the performance of many organizations.

The evidence, as noted from the results are significant. Also more interesting is that, the performance can easily be traced to the improved effective leader capacity development for individual employees engaged on the program.

\section{RECOMMENDATIONS}

This recommendation is based on the results and analysis of this research study. It is the details collected from the respective respondents of the research questionnaire administration that has made this recommendation meaningful for the purpose.

It is very clear that, for organizations to perform better and realize their strategic goal through its implementation, they encounter many challenges and competing demands from other players within the business arena.

In order to pull through the challenges and competing demands, research shows that there is need to have in place a team of employees that would be referred to as effective leaders. This team should 
comprise the senior management and all employees who by their individual task contribute to the organizations overall strategic goals.

This research study has proved that, by providing effective leader capacity development at all levels in an organization, it builds a team of effective leaders.

By doing so, employees have a purpose and will improve their level of responsibility at every action in executing their tasks. They improve their communication skills internally and externally for the benefit of the organization and themselves as individuals.

Research shows that, following capacity development of employees into effective leaders, there is team spirit among employees that is exhibited.

Therefore, it is recommended that organizations consider employee leader capacity development as a main strategic goal for the short and the long-term wins in its overall performance if it has to survive in a hash and competing environment of doing good business.

\section{REFERENCES}

[1] Anderson, Bob; Adams, Bill. Leadership Excellence Essentials, Mar2016, Vol. 33 Issue 3,p5-6,2pSix Leadership Practices.

[2] Bass, B. M. (2008). Handbook of leadership: Theory, research, and managerial applications (4th ed.). New York: Free Press.

[3] Berson, Y., Nemanich, L. A., Waldman, D. A., Galvin, B. M., \& Keller, R. T. (2006). Leadership and organizational learning: A multiple levels perspective. Leadership Quarterly, J 7, 577-594.

[4] Cameron, K. (2011). Responsible leadership as virtuous leadership, journal of Business Ethics, 98, 25-35.

[5] Carson, J., Tesluk, P., \& Marrone, J. (2007). Shared leadership in teams: An investigation of antecedent conditions and performance. Academy of Management Journal, 50, 1217-1234.

[6] CAStellano, STEPHANIE. TD: Talent Development, Dec2014, Vol. 68 Issue 12, p66-68, 3pReflections on Leadership.

[7] Chase, Ashley Krenelka; Frentzen, Ellen. AALL Spectrum, Jul2015, Vol. 19 Issue 9, p22-24, 3pLeadership, Management, and Professional Development.

[8] DeRue, D. S., Nahrgang, J., Wellman, N., \& Humphrey, S. E. (2011). Trait and behavioral theories of leadership: An integration and meta-analytic test of their relative validity. Personnel Psychology, 64(1), 752

[9] Dowsett, Christopher Strategic Finance, December 2006, Vol. 88 Issue 6, p25-55, 2p-Effective Leadership

[10] Hanbury, George L.; Sapat, Alka; Washington, Charles W.. Public Administration Review, Sep/Oct2004,

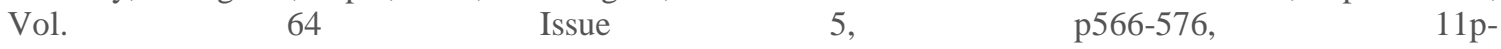
Know Yourself and Take Charge of Your Own Destiny: The "Fit Model" of Leadership.

[11] Hassan, Shahidul; Wright, Bradley E.; Yukl, Gary. Public Administration Review, May2014, Vol. 74 Issue 3, p333-343, 1p,-Does Ethical Leadership Matter in Government? Effects on Organizational Commitment, Absenteeism, and Willingness to Report Ethical Problems.

[12] Fairholm, Matthew R.. Public Administration Review, Sep/Oct2004, Vol. 64 Issue 5, p577-590, 14pDifferent Perspectives on the Practice of Leadership.

[13] FOX, JENA TESSE. Hotel Management (21582122), 10/17/2017, Vol. 232 Issue 14, p42-42, 1pKENYA BANNISTER: GENERAL MANAGER, COURTYARD LONG BEACH AIRPORT LONG BEACH, CALIF.

[14] Jenkins, Dela; Institute of Leadership \& Management (Great Britain). Series: ILM Superseries. Edition: 4th ed. Dela Jenkins. Oxford: Routledge. 2003. eBook., Database: eBook Collection (EBSCOhost)-Managing Relationships at Work

[15] Kaiser, R. B., Hogan, R., \& Craig, S. B. (2008). Leadership and the fate of organizations. American Psychologist,63(2), 96-110.

[16] Kaiser, R. B., \& Overfield, D. V. (2010). Assessing flexible leadership as a mastery of opposites. Consulting Psychology Journal: Practice and Research, 62, 105-118.

[17] Kumar et al (2013)-International Journal of Leadership Studies, Vol. 8, Iss. 1, 2013, pp. 19-31

[18] KRIDLER, MATT. Public Management (00333611), May2016, Vol. 98 Issue 4, p20-21, 2p-ON THE LEADERSHIP PATH. 
[19] Leadership Excellence Essentials, Jul2016, Vol. 33 Issue 7, p24-25, 2p-The Leadership Challenge.

[20] LEE STALLARD, MICHAEL. TD: Talent Development, Apr2015, Vol. 69 Issue 4, p48-52, 5p Connect to ENGAGE.

[21] Mewborn, Amanda. Industrial Engineer: IE, Jul2017, Vol. 49 Issue 7, p22-22, 1p,- Find peers with similar interests.

[22] Rocco, Tonette S. New Horizons in Adult Education \& Human Resource Development, Summer2016, Vol. 28 Issue 3, p1-2, 1p- A Reflection on Dysfunctional Leadership and Leadership Misplacement.

[23] Wang, H., Tsui, A. H., \& Xin, K. R. (2011). GEO leadership behaviors, organizational performance, and employee attitudes. Leadership Quarterly, 22, 92-105

[24] Shafiqul Alam, Md. Ruhul Amin Mollah, Samiul Parvez Ahmed, International Journal of Management Finance and EducationVolume: 08, Issue: 02, 2015-https://www.researchgate.net/publication/283566409

[25] Weinberg, Hugh. Public Administration Review, May2014, Vol. 74 Issue 3, p344-345, 1p.-Commentary: Ethical Leadership in Public Service: A Solid Foundation for Good Government.

[26] Yukl, G. (2012) Effective Leadership Behavior. Vol. 26 Issue 4, p66-85

[27] Yukl, G. (2013). Leadership in organizations (8th ed.). Englewood

[28] Cliffs, NJ: Prentice Hall

[29] Yukl, Gary A.; Lepsinger, Richard. San Francisco : Pfeiffer. 2004. eBook-Flexible Leadership : Creating Value by Balancing Multiple Challenges and Choices

[30] Yukl, G. (2008). How leaders influence organizational effectiveness. Leadership Quarterly, 19, 708-722.

[31] Yukl, G. (2013). Leadership in organizations (8th ed.). Englewood Cliffs, NJ: Prentice Hall.

[32] Yukl, G., Gordon, A., \& Taber, T. (2002). A hierarchical taxonomy of leadership behavior: Integrating a half century of behavior research, journal of Leadership and Organizational Studies, 9, 15-32.

\section{AUTHORS' BIOGRAPHY}

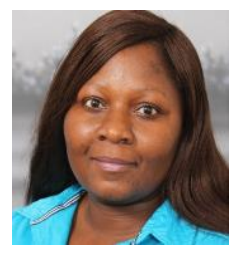

Angela Samundengo, Obtained MSc Degree in Project Management from Roehampton University in London. Currently a PhD student in Project Management at AIU and finalized her thesis in December 2019 with a research focus on effective leader in diverse environment. Before embarking on her research work, both at master's degree and $\mathrm{PhD}$, Samundengo has a background in Financial management qualifications obtained from ACCA at various levels. Her career has evolved around financial and programmes management in international organizations. Currently, Samundengo holds a position of Country Deputy programmes Manager at VVOB in Lusaka Zambia.

Citation: Angela Samundengo. "Organizational Management through Effective Leadership in Diverse Environment" International Journal of Managerial Studies and Research (IJMSR), vol 8, no. 10, 2020, pp. 3457. doi: https://doi.org/10.20431/2349-0349.0810005.

Copyright: (C) 2020 Authors. This is an open-access article distributed under the terms of the Creative Commons Attribution License, which permits unrestricted use, distribution, and reproduction in any medium, provided the original author and source are credited. 